\title{
Reflets
}

Revue ontaroise d'intervention sociale et communautaire

\section{Collaborer pour mieux résister aux effets des coupures}

\section{Sonja Marion}

Volume 3, numéro 1, printemps 1997

Enfance et familles en contexte d'appauvrissement

URI : https://id.erudit.org/iderudit/026161ar

DOI : https://doi.org/10.7202/026161ar

Aller au sommaire du numéro

Éditeur(s)

Reflets : Revue ontaroise d'intervention sociale et communautaire

ISSN

1203-4576 (imprimé)

1712-8498 (numérique)

Découvrir la revue

Citer cet article

Marion, S. (1997). Collaborer pour mieux résister aux effets des coupures.

Reflets, 3(1), 162-164. https://doi.org/10.7202/026161ar

Tous droits réservés (C) Reflets : Revue ontaroise d'intervention sociale et communautaire, 1997

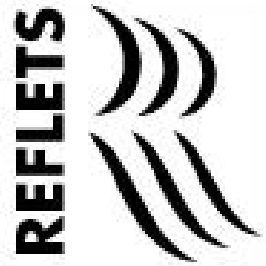

Ce document est protégé par la loi sur le droit d'auteur. L'utilisation des services d'Érudit (y compris la reproduction) est assujettie à sa politique d'utilisation que vous pouvez consulter en ligne.

https://apropos.erudit.org/fr/usagers/politique-dutilisation/ 


\section{Collaborer pour mieux résister aux effets des coupures}

\section{Sonja Marion}

Centre Phoenix pour enfants et familles, Renfrew

Que ce soit au niveau des conditions de travail dans le domaine de l'éducation ou au niveau de la prestation des services sociaux et de santé, nous avons tous été touchés par les coupures de ressources. Les services sociaux francophones en milieu minoritaire $\mathrm{du}$ Centre Phoenix pour enfants et familles ont aussi subi l'impact de ces coupures et ont dû s'y adapter.

Les seuls services de santé mentale francophones offerts dans le comté de Renfrew rejoignent la communauté francophone par le truchement de ses quatre écoles, selon l'entente entre le Centre Phoenix et la Section de langue française du Conseil scolaire catholique séparé du comté. Il en est de même pour les services psychologiques offerts dans ces écoles selon une entente avec une firme d'Ottawa.

Les services spécialisés sont valorisés et priorisés par la Section de langue française de ce Conseil scolaire. Conséquemment, on a tenté de minimiser la portée des restriction budgétaires. En effet, au niveau des services sociaux scolaires, elles n'ont affecté le travail que pour une semaine en saison estivale. Les services psychologiques au secondaire pour lesquels le financement a été retiré ont été repris par la conseillère en orientation.

La Section de langue française honore aussi une entente avec la seule maison d'hébergement pour femmes et enfants violentés du comté. Cette entente s'actualise dans le cadre d'un poste de prévention de la violence dans les écoles financées par le ministère 
de l'Éducation. Une intervenante de la maison assure la transition des enfants à leur école d'accueil pendant leur séjour en milieu d'hébergement. Les deux thérapeutes du Centre Phoenix oeuvrant dans les écoles répondent aux demandes des francophones.

Ce mandat a créé un travail de collaboration étroite entre les deux thérapeutes et la coordonnatrice des ressources du Conseil scolaire. Cette dernière travaille aux projets francophones de façon bénévole. Certains projets ainsi créés ont facilité la participation des directions d'écoles au sein de comités qui oeuvrent toujours, tel le comité sur le harcèlement sexuel entre élèves. Ces directions d'écoles ont à leur tour invité des professeurs à siéger sur ce comité afin de bénéficier de leur expertise lors de la création de guides d'intervention. De plus, un sous-comité a été mis sur pied pour organiser, en novembre dernier, la journée de développement professionnel consacrée à la problématique de la violence. Lors de ces journées pédagogiques, tous les employés des quatre écoles sont invités: surintendant, directeurs, professeurs, secrétaires, concierges et même le curé de la paroisse. Toutes les écoles bénéficient du travail d'équipe et du partage de l'expertise.

Un comité de l'École secondaire catholique Jeanne-Lajoie collabore avec les thérapeutes et la coordonnatrice des ressources du Conseil scolaire. Ce comité $x$, créé par les élèves de cette école il y a quelques années, organise mensuellement des activités pour et avec les élèves. À chaque année, ces derniers priorisent les thèmes connexes à la violence, tels l'estime de soi, la dépendance, etc. Ces activités ont aussi bénéficié de l'apport financier provenant du volet de prévention de la violence dans les écoles du ministère de l'Éducation. Lorsque le ministère a alloué des argents à ce poste au printemps dernier, les thérapeutes ont pu se procurer quelques ressources et programmes en français. Cette denrée rare est très appréciée: les thérapeutes ont enfin des outils de travail. L'automne dernier, le comité $x$ a mis en commun ses derniers sous avec ceux d'organismes à but non lucratif de la communauté afin d'organiser des activités dynamiques pour les élèves des niveaux intermédaire et secondaire, entres autres, une équipe de la Maison des Jeunes d'Ottawa qui viendra leur offrir un outil d'évaluation de la dépendance aux drogues et à l'alcool et celle du programme 
Réseau-Ado du Centre hospitalier pour enfants de l'Est ontarien qui abordera avec, ces élèves, certains sujets qu'ils auront priorisés.

Le concours organisé conjointement avec le Centre d'aide et de lutte contre l'agression sexuelle entre dans sa deuxième phase. Les élèves du secondaire produiront un (ou plusieurs) vidéo qui servira ensuite d'outil d'information et de prévention pour la clientèle francophone. Suite à une suggestion du comité $x$, ce centre d'aide considère présentement la possibilité de défrayer la majorité des coûts reliés à l'achat d'une caméra-vidéo qui servira à produire cet outil de travail au lieu d'offrir plusieurs prix, comme en juin dernier.

Le mandat du poste du ministère de l'Éducation pour la prévention de la violence a facilité le travail d'équipe. Ce travail d'équipe avec des personnes ressources provenant de divers milieux, qu'elles soient concierges, administrateurs ou communautaires, a favorisé une variété d'interventions qui ont contribué à l'amélioration des conditions de travail des thérapeutes, l'expansion des services francophones et le développement de l'expertise entre ces parties.

Ce partenariat continue de se faire malgré restrictions des ressources et les incertitudes des revenus. En effet, dans un tel climat, les partenariats et le travail d'équipe deviennent des conditions essentielles au maintien de services de qualité. 